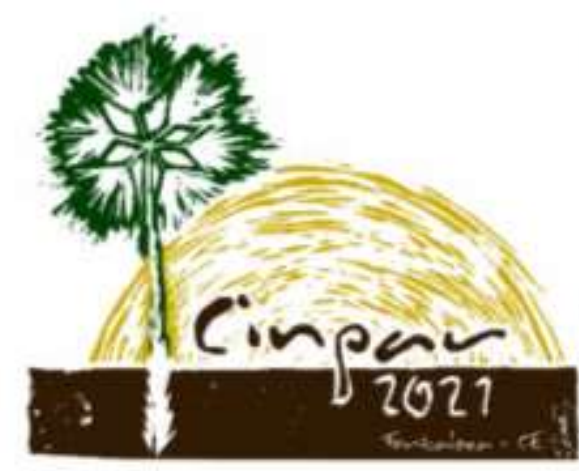

XVII Congresso Internacional sobre Patologia e Reabilitação das Construções

XVII Congreso Internacional sobre Patologia y Rehabilitación de las Construcciones

XVII International Conference on Pathology and Constructions Rehabilitation

FORTALEZA (Brasil), 3 a 5 de junho de 2021 https://doi.org/10.4322/CINPAR.2021.056

\title{
Manifestações Patológicas e Reabilitação de Estruturas de Concreto Armado - Edifício Vilanova Artigas - FAU-USP
}

\section{Pathological Manifestations and Rehabilitation of Reinforced Concrete Structures - Vilanova Artigas Building - FAU-USP}

\author{
Leonardo INOJOSA ${ }^{1}$, João da Costa PANTOJA², Márcio Augusto Roma BUZAR ${ }^{3}$ \\ ${ }^{1}$ Faculdade de Tecnologia, Dep. de Engenharia Civil e Ambiental - UnB, Brasília, Brasil, leinojosa@gmail.com \\ ${ }^{2}$ PPG da Faculdade de Arquitetura e Urbanismo - UnB, Brasília, Brasil, joaocpantoja@gmail.com \\ ${ }^{3}$ PPG da Faculdade de Arquitetura e Urbanismo - UnB, Brasília, Brasil, marcio.buzar@gmail.com
}

Resumo: $O$ edifício Vilanova Artigas, que abriga a Faculdade de Arquitetura e Urbanismo da Universidade de São Paulo - FAU USP pode ser descrito como um grande bloco envolvido por grandes empenas de concreto armado suspensas por pilares trapezoidais duplos (pilares Artigas). O edifício que hoje leva o nome do arquiteto que o concebeu juntamente com Carlos Cascaldi, foi construído entre 1967 e 1969 e, portanto, se enquadra no grupo de edificações modernistas em concreto armado com mais de 50 anos de uso. Considerado um dos principais representantes do modernismo arquitetônico no Brasil e pertencente à chamada "arquitetura brutalista" própria da década de 60 em São Paulo, o edifício Vilanova Artigas é considerado patrimônio arquitetônico tanto pelo CONDEPHAAT quanto pelo COMPRESP. Este trabalho visa fazer um estudo do panorama das diversas manifestações patológicas encontradas nas estruturas de concreto armado da edificação ao longo de sua vida útil, bem como expor e analisar as intervenções propostas e executadas ao longo dos anos, culminando na última grande intervenção realizada entre $2012 \mathrm{e}$ 2015, fazendo uma correlação entre as tomadas de decisão e implementações nesse estudo de caso e a conservação do patrimônio.

Palavras-chave: Concreto armado, Manifestações patológicas, reabilitação de estruturas.

Abstract: The Vilanova Artigas building, which houses the Faculty of Architecture and Urbanism of the University of São Paulo - FAU USP can be described as a large block surrounded by large reinforced concrete walls suspended by double trapezoidal pillars (Artigas pillars). The building that today bears the name of the architect who conceived it together with Carlos Cascaldi, was built between 1967 and 1969 and therefore falls into the group of modernist buildings in reinforced concrete, with about 50 plus years of use. Considered one of the main representatives of architectural modernism in Brazil and belonging to the so-called "brutalist architecture" of the 1960s in São Paulo, the Vilanova Artigas building is considered an architectural heritage by both CONDEPHAAT and COMPRESP. This work aims to make a study of the panorama of the various pathological manifestations found in the reinforced concrete structures of the building throughout its useful life, as well as to expose and analyze the interventions proposed and executed over the years, culminating in the last major intervention carried out between 2012 and 2015, making a correlation between decisionmaking and implementations in this case study and the conservation of heritage.

Key-words: Reinforced concrete, Pathological manifestations, rehabilitation of structures. 


\section{Introdução}

O projeto de arquitetura leva em consideração de diversos fatores, do funciona ao estético, passando também pelo econômico, cultural e social. A conciliação de todos esses fatores e também entre diversas disciplinas dá ao projeto arquitetônico o seu caráter de complexidade. Uma das conciliações mais importantes nesse aspecto é a integração entre a arquitetura e a estrutura. A estrutura é uma parte na concepção da arquitetura, sem a qual a arquitetura não seria possível, pois não há forma sem estrutura. Não há intenção plástico-espacial que se viabilize sem o apoio da técnica construtiva (PASQUA, 2017).

A história é repleta de exemplos nos quais a perfeita integração entre arquitetura e estrutura permitiu a execução de notáveis obras, aproveitando-se inteligentemente dos materiais e das técnicas disponíveis. Neste trabalho é apresentado um estudo do edifício da FAU/USP (Figura 1), projetado por Vilanova Artigas. Nesse estudo são destacados, por meio de análises numéricas os elementos estruturais protagonistas no processo de criação do espaço e da forma arquitetônica. Estabelecidas as funções estruturais, são analisadas as diversas manifestações patológicas encontradas nas estruturas de concreto armado da edificação ao longo de sua vida útil, além das intervenções propostas e executadas ao longo dos anos, culminando na última grande intervenção realizada entre 2012 e 2015, fazendo uma correlação entre as tomadas de decisão e implementações nesse estudo de caso e a conservação do patrimônio.

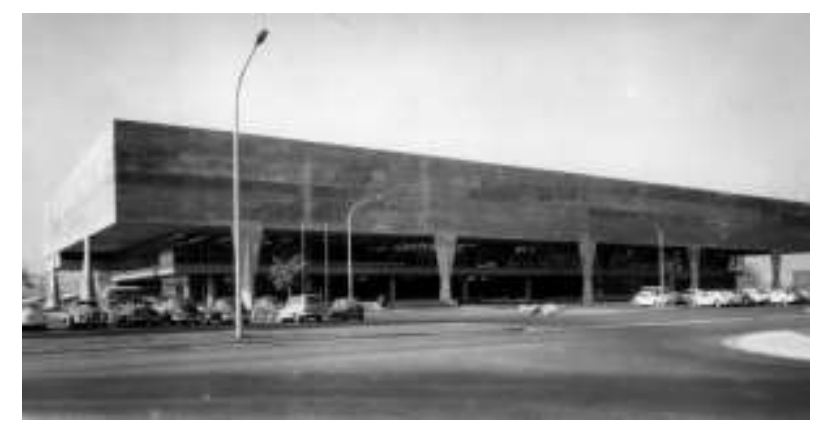

Figura 1 - Fachada do edifico Vilanova Artigas. Fonte: Acervo Biblioteca FAU-USP.

A Faculdade de Arquitetura e Urbanismo da Universidade de São Paulo (FAUSP), situada na cidade de São Paulo, nasce da separação do curso de arquitetura das engenharias agrupadas na Escola Politécnica. Inicialmente, a faculdade ocupou um casarão, construído em estilo art noveau, no bairro de Higienópolis, doado pela família Penteado, com a condição de abrigar uma faculdade de arquitetura, onde ficou de 1949 a 1968. Posteriormente, com a revisão da grade curricular e a necessidade de mais espaço, a faculdade foi remanejada para a Cidade Universiária, onde ganhou um novo edifício projetado por João Batista Vilanova Artigas e Carlos Cascaldi.

Vilanova Artigas é reconhecido como um dos principais arquitetos brasileiros do século XX e provavelmente o mais influente no contexto da arquitetura paulista. Entre os anos de 1946 a 1952, seus projetos são marcados pela influência de Le Corbusier e Niemeyer. Passam a constar, no seu vocabulário construtivo, volumes geométricos puros apoiados sobre pilotis, grandes aberturas, brises e rampas (GIANNECCHINI, 2009). E, de 1952 até o final de sua carreira, caracteriza sua fase brutalista, na qual se encontram seus projetos de maior destaque. E é justamente nesse último período que a estrutura ganha maior relevância na conformação de seus projetos, passando a ser sua essência.

O edifício da FAUUSP notabiliza-se pela racionalidade construtiva, pela riqueza espacial e pelo aspecto didático com que evidencia os elementos construtivos e o partido arquitetônico para os usuários do prédio, predominantemente estudantes de arquitetura. Além de ser um dos mais importantes edifícios da chamada escola paulista de arquitetura.

Externamente o edifício caracteriza-se por um volume retangular em concreto aparente, suspenso do chão, apoiado sobre pilares esculturais. Os dois pavimentos abaixo desse volume (térreo e primeiro pavimento) se encontram recuados em relação aos pilares da fachada, formando um peristilo ao redor da edificação, sua vedação é em caixilharia que vai do piso ao teto, com exceção da parte frontal do prédio, na qual não há nenhum tipo de porta ou fechamento, tornando o acesso generoso e convidativo, integrando interior e exterior. 
Internamente é como se fossem dois volumes de quatro pavimentos separados por um vazio central, e por uma diferente de meio nível entre os pavimentos dos lados opostos do vazio. Uma mesma cobertura com 960 domos unifica ambos os volumes. Em contraposição a sobriedade e unicidade da forma externa, a espacialidade interna é muito dinâmica, fruto do jogo de avanços e recuos das lajes sobre o vazio central, da alternância de aberturas e fechamentos e da generosidade dos espaços de circulação. Além disso, as aberturas da cobertura fechada apenas pelos domos permitem a entrada de luz natural em praticamente todo o edifício (Figura 2).

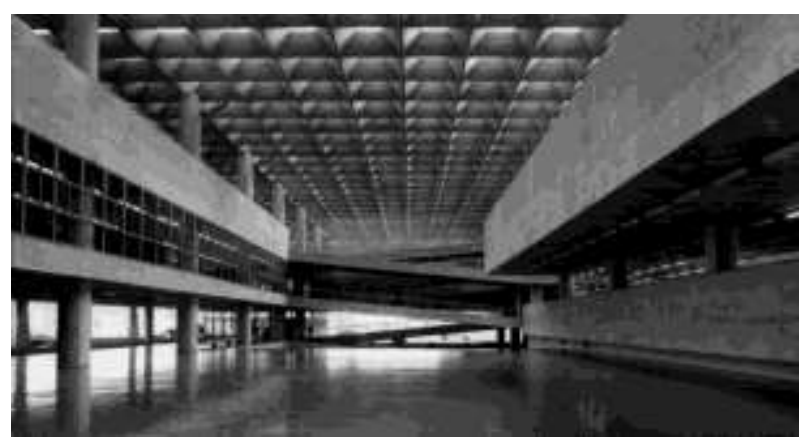

Figura 2 - Vista interna do vão central (Salão Caramelo) do edifico Vilanova Artigas. Foto de Nelson Kon.

\section{Estrutura}

O projeto estrutural é da autoria do Escritório Técnico J. C. de Figueiredo Ferraz e a construção foi executada pela Construtora ANR, Alberto Nagib Rizkallah Ltda. O concreto armado foi a técnica construtiva adotada na quase totalidade do prédio, não somente nas fundações, vigas e pilares, mas também na cobertura e em grande parte das vedações. A estrutura é hiperestática e as lajes, juntamente com as vigas, formam caixões perdidos. O edifício segue uma modulação de $11 \times 11$ metros. A cobertura é estruturada no sentido longitudinal por 4 vigas invertidas separadas entre si por 22 metros. No sentido transversal, há vigas invertidas a cada 11 metros.

A estrutura do edifício se desenvolve nos níveis descritos pela arquitetura, criando grandes vãos e balanços, sustentados pelas grandes lajes nervuradas e grandes empenas de concreto armado. Para análise da estrutura, foi feita uma modelagem dos elementos estruturais no software SAP-2000, utilizando como base os desenhos arquitetônicos disponíveis na biblioteca da FAU-USP.

\subsection{Análise da Estrutura}

Para modelo estudado (Figura 3) foram usados elementos barras (frames) - para os pilares e vigas da cobertura e placas (area shells) para as lajes, nervuras, vigas longitudinais e empenas, resultando em um modelo composto por 2.164 frames, 26.926 area shells, 19.194 points e um total de 107.689 area edges.

As cargas utilizadas no modelo foram inseridas de acordo com o estabelecido nas normas ABNT NBR 6118:2014 e 6120:2017 para o peso próprio da estrutura de concreto armado $\left(25 \mathrm{kN} / \mathrm{m}^{3}\right)$, além da carga acidental indicada para áreas de exposição e escolas $\left(5 \mathrm{~N} / \mathrm{m}^{2}\right)$.

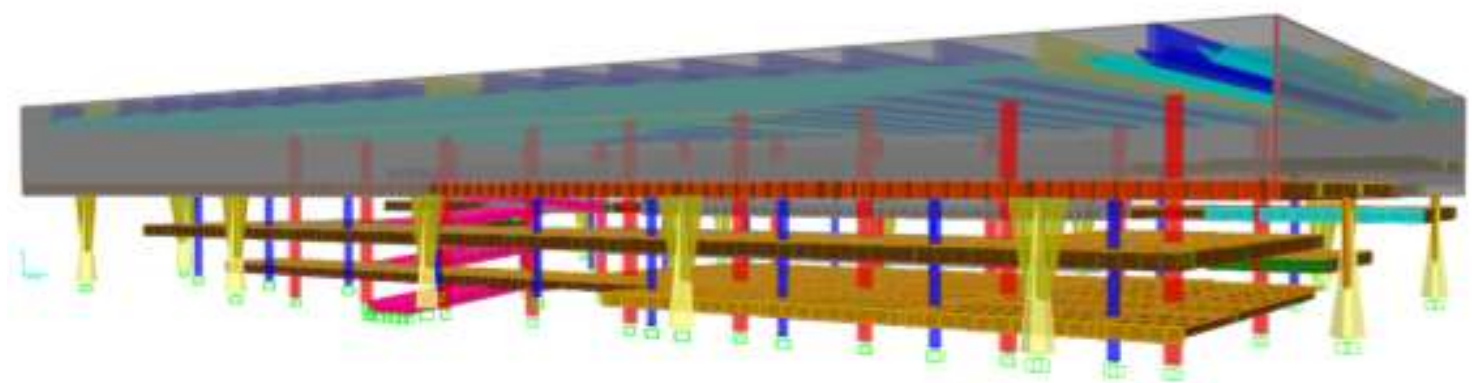

Figura 3 - Modelo do Edifício Vilanova Artigas. Desenho dos Autores, Programa SAP 2000. 
$\mathrm{Na}$ análise dos deslocamentos na estrutura, foi utilizada a combinação de carga para o Estado Limite de Serviço (ELS) (Equação 1). Já para a análise de esforços e dimensionamento foi utilizada a combinação de carga para Estado Limite Último (ELU)

Os pilares das fachadas são formados por duas pirâmides que se encaixam pelas pontas, a base não converge para o mesmo ponto que a parte superior, seus vetores se cruzam no meio do caminho, criando uma composição dinâmica como se a pirâmide superior representasse toda a carga do edifício, enquanto a inferior representasse a força de reação da fundação

Podemos observar na Figura 4 que carga máxima sobre um dos pilares das extremidades da fachada frontal é de aproximadamente 300 toneladas. A tensão nessa altura do pilar é 6,25 Mpa. Logo, na menor seção, encontramos um coeficiente de segurança de 5,12; bem acima do coeficiente na ordem de 1,4, normalmente utilizado em estruturas de concreto armado. Portanto, podemos afirmar que o fator determinante para a menor seção do pilar não foi a resistência à compressão. Importante enfatizar que, como os vãos ente os pilares são grandes -11 metros - deve ser levado em consideração no dimensionamento a estabilidade do conjunto da edificação.

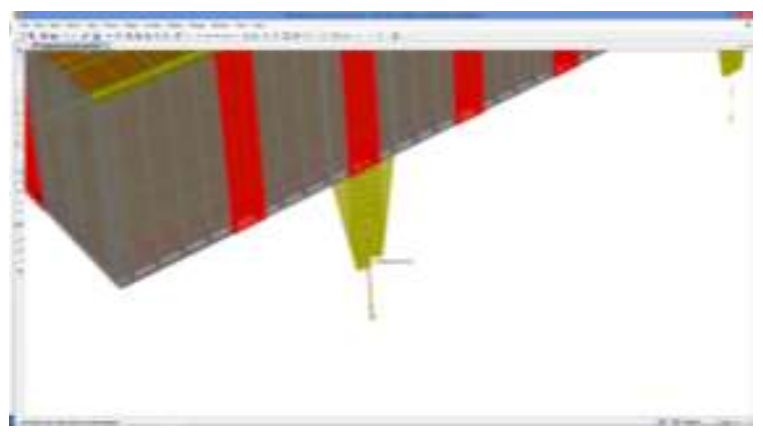

Figura 4 - Diagrama de Esforços Normais. Desenho dos Autores, Programa SAP 2000.

Outra característica do projeto do edifício Vilanova Artigas que chama atenção são os balanços das lajes nervuradas que formam os pisos, gerando relações de cheios e vazios e destacando as massas de concreto aparente sobre os espaços internos da edificação. Apesar dos balanços chegarem a $12 \mathrm{~m}$ de comprimento em alguns casos, a grande rigidez da estrutura não permite grandes deslocamentos.

Como podemos ver na Erro! Fonte de referência não encontrada., que mostra o modelo internamente, o balanço mais expressivo do ponto de vista estético - formado pela projeção do nível dos Departamentos sobre o Salão Caramelo - apresenta um deslocamento de menos de $2 \mathrm{~cm}$ verticalmente. 0 maior deslocamento vertical entre os diversos balanços da estrutura, as extremidades da laje do piso dos Departamentos apresentam deslocamento de cerca de $4 \mathrm{~cm}$.

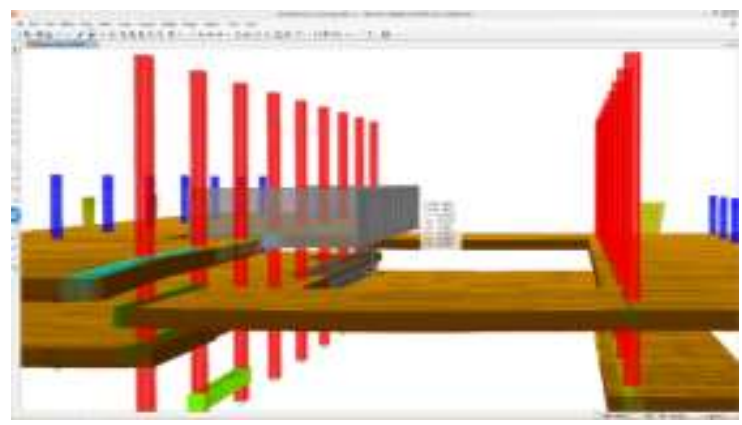

Figura 5 - Diagrama de Deslocamentos - vista interna do edifício. Desenho dos Autores, Programa SAP 2000.

O sistema usado na cobertura do edifício é a associação transversal entre vigas conhecido como grelhas. Nas grelhas as vigas são colocadas lado a lado, com vão pequenos, assim como em uma laje nervurada, a diferença é que no caso das grelhas as vigas se repetem nas duas direções, com ligações rígidas nos cruzamentos entre elas, proporcionando assim uma colaboração entre as vigas (REBELLO, 2000).

A grelha, na proporção utilizada na cobertura do edifício Vilanova Artigas $-L<\mid$ - permite a distribuição dos esforços nas duas direções, aumentando a rigidez do sistema estrutural e é formada por três tipos de vigas 
espaçadas em 2,75m - vigas baixas, vigas invertidas e vigas invertidas com juntas de dilatação. As vigas formam calhas para receber as águas das chuvas e os espaços entre elas são fechados com domos de iluminação zenital, proporcionando a iluminação natural em todo o interior do edifício.

As empenas do prédio da FAU-USP são grandes vigas-parede, a frontal e lateral possuem $8,15 \mathrm{~m}$ de altura, sendo a frontal com 110 metros de comprimento e 5 pontos de apoio (vãos de 22 metros e balanços de 11 metros para cada lado), e as laterais com 66 metros de comprimento e 2 pontos de apoio (vãos de 33 metros e balanços de 16,5 metros). A empena posterior tem 7,25 metros de altura e acompanha as dimensões e apoios da empena frontal (110 metros).

\section{Intervenções Corretivas}

Ao longo de sua história, o Edifício Vilanova Artigas já passou por diversas intervenções para remediar determinadas manifestações patológicas identificadas em sua estrutura.

Conforme informações levantadas no Relatório Técnico PhD 136 / 2010, elaborado em 2010 pela empresa PHD (ANTUNES et al, 2010), para preservar este edifício de importância cultural, histórica e arquitetônica, foram necessários reparos e obras de pequena e de grande escala em locais como na portaria, diretoria, jardins, reforço de pilar de fachada e até na cobertura do edifício.

Em 2001 foi executada a recuperação e reforço do apoio doe pilar externo (na fachada) sob a junta central do edifício. Na ocasião, o pilar apresentava desagregação na extremidade superior com exposição da armadura, sendo necessário substituir o aparelho de apoio e reconstruir o concreto destruído, nos dois elementos - pilar e fundo da viga-parede.

Entre 1995 e 2009 o edifício passou por diversas intervenções corretivas. Inicialmente, parte da cobertura sofreu uma intervenção de grande importância, para solucionar graves problemas de infiltração, quando foram necessárias, entre outras intervenções, o suporte de parte da cobertura com tirantes através do uso de estrutura metálica especialmente construída para esse fim, a retirada do sistema existente de impermeabilização, a demolição da laje estrutural de cobertura, o esgotamento da água aprisionada nas vigas tipo $V$, a instalação de novos caixões perdidos dentro dessas vigas, a reconstrução da laje estrutural de cobertura e a impermeabilização da laje para obtenção de estanqueidade.

Entre 2009 e 2010 foram reformadas as salas dos Departamentos, intervenção que incluiu a recuperação estrutural desse setor, assim como outras áreas administrativas do edifício, situadas no pavimento térreo. Ainda nesse período, foi identificada a necessidade de recuperação estrutural das grandes vigas estruturais invertidas que formam a grelha da cobertura. Na ocasião, foram constatados pontos com som cavo, armaduras expostas e avançado processo de corrosão

Além dessas intervenções nas grandes vigas invertidas, também foram reconstituídas na ocasião, todas as juntas de dilatação (Figura 6).
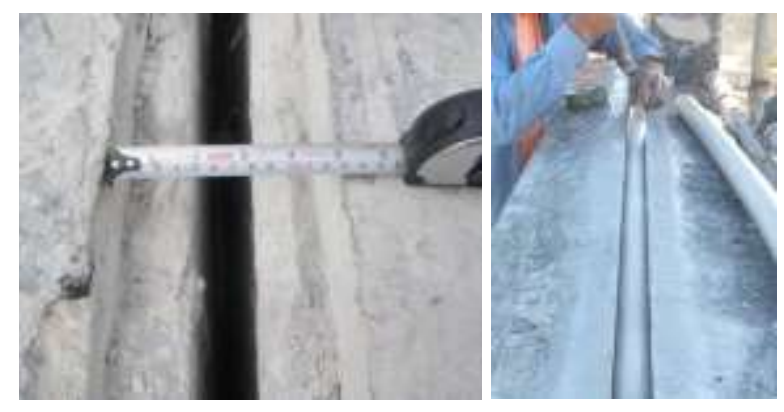

Figura 6 - Juntas com espessura acima de 40mm (reforço de borda, posicionamento do tarucel e selante). Fotos: Relatório Técnico PhD 136 / 2010

Em 2010, foram identificadas diversas manifestações patológicas, que culminaram primeiramente no relatório Relatório Técnico PhD 136 / 2010 (ANTUNES et al, 2010). Entre as manifestações patológicas encontradas destacam-se (Figura 7 a Figura 10): 

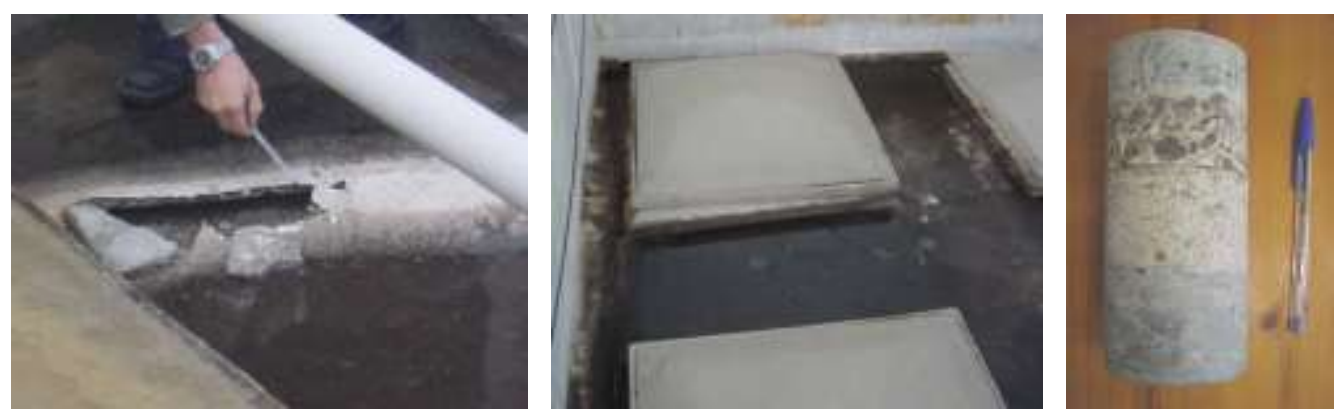

Figura 7 - Juntas Sistema de impermeabilização rompido em pontos isolados da laje de cobertura,; Inexistência de caimento em muitos trechos de laje com acúmulo de água; Sobreposição indevida de várias camadas de sistemas de impermeabilização anteriores; Fotos: Relatório Técnico PhD 136 / 2010
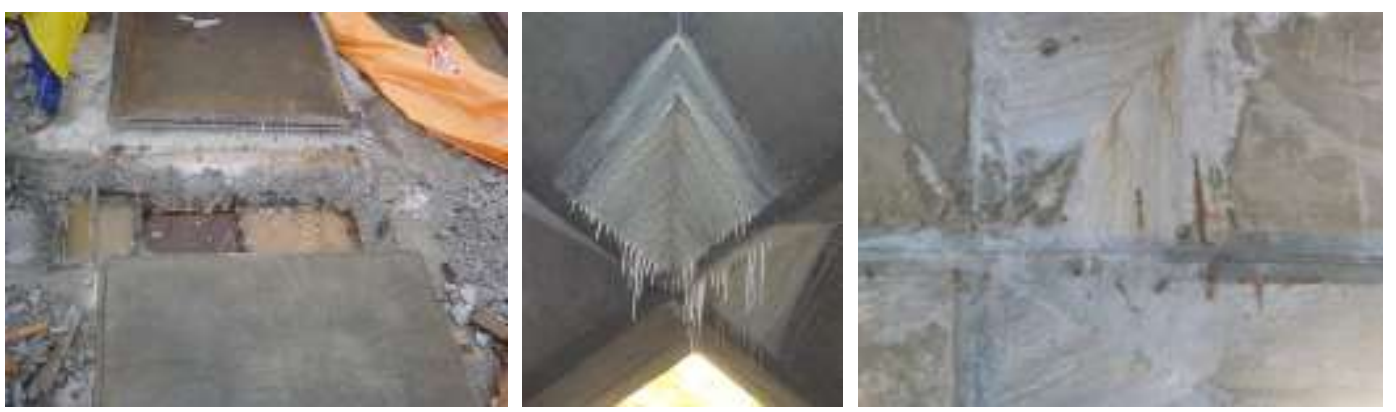

Figura 8 - Presença de água em partes internas da estrutura; Presença de eflorescências na superfície inferior da laje estrutural de cobertura, manifestada na forma de manchas e estalactites esbranquiçadas; Em pontos isolados da face inferior da laje existe a ocorrência de corrosão de armaduras; Fotos: Relatório Técnico PhD 136 / 2010
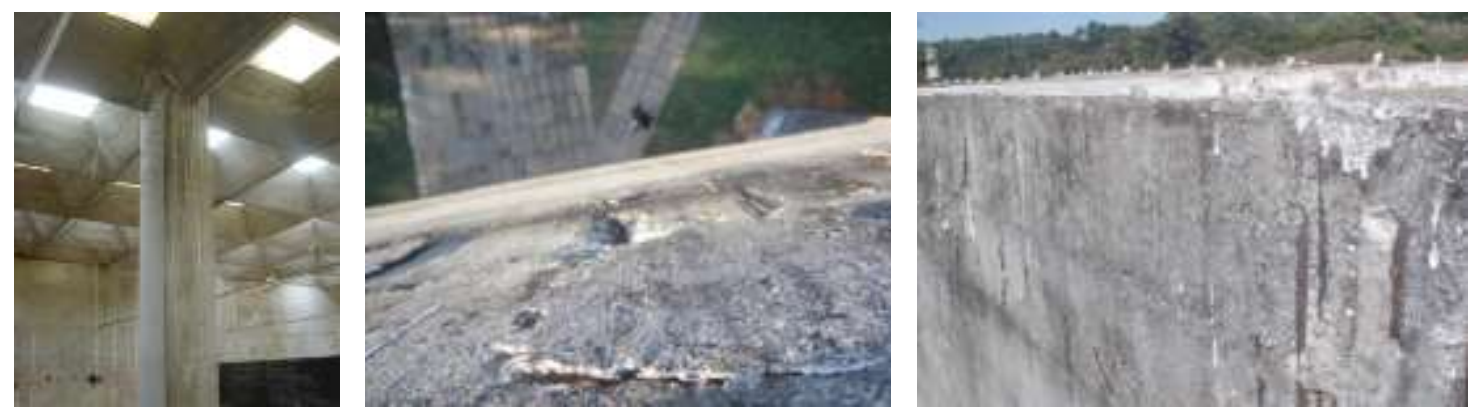

Figura 9 - Deficiência de estanqueidade da união entre o ralo e o duto de escoamento de águas pluviais embutido nos pilares; Corrosão das armaduras, e em muitos casos com desplacamento do concreto de cobrimento, em diversas regiões (fachada externa); Inexistência de cobrimento adequado, em diversas regiões da empena perimetral, com Exposição da armadura. Fotos: Relatório Técnico PhD 136 / 2010
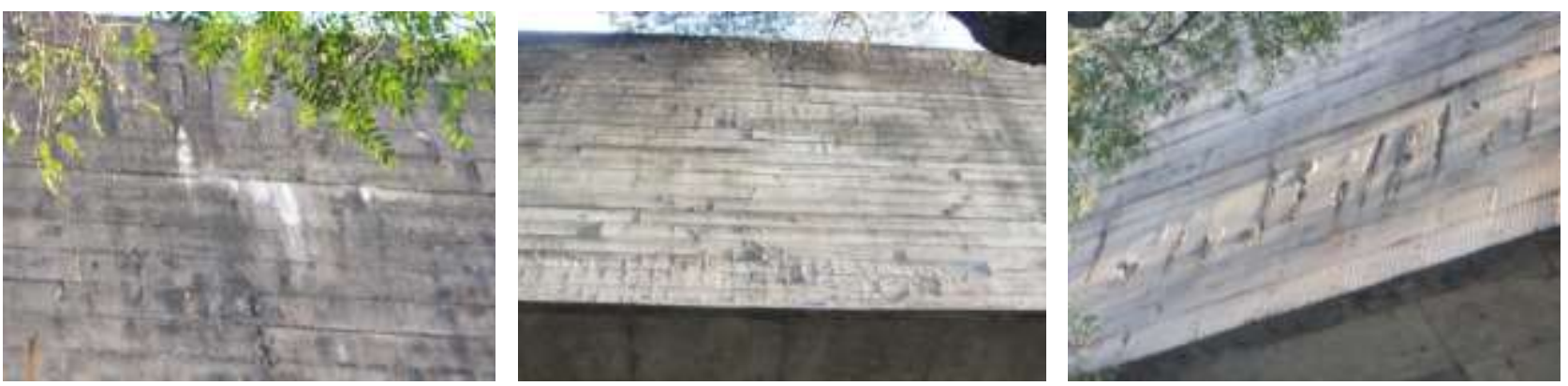

Figura 10 -Manchas de eflorescência e de corrosão na fachada devido ao cobrimento inferior a 5mm; Desplacamento do concreto e conseqüente exposição de armadura na fachada; Deposição de fuligem, desenvolvimento de bolor, de corrosão de armadura com desplacamento de concreto do cobrimento e exposição do aço na empena perimetral.

Fotos: Relatório Técnico PhD 136 / 2010

Posteriormente, em uma grande intervenção realizada entre 2012 e 2015 (FIG) foram executados os procedimentos mostrados na Tabela 1. 
Tabela 1 - Intervenções executadas entre 2012 e 2015.

\begin{tabular}{|c|c|}
\hline Intervenção & Reabilitação da face superior da laje de concreto da cobertura \\
\hline Procedimentos & $\begin{array}{l}\text { 1. Demolição e retirada das camadas de impermeabilização existentes; } \\
\text { 2. Percussão e observação visual para determinar áreas a recuperar; } \\
\text { 3. Delimitação das áreas a serem reparadas, com disco de corte; } \\
\text { 4. Escarificação do concreto contaminado com martelete; } \\
\text { 5. Limpeza das armaduras; } \\
\text { 6. Restituição das armaduras; } \\
\text { 7. Preparação da superfície por saturação com água; } \\
\text { 8. Especificação da argamassa estrutural de reparo; } \\
\text { 9. Preenchimento com a argamassa estrutural de reparo; } \\
\text { 10. Cura úmida por aspersão de água; }\end{array}$ \\
\hline Intervenção & $\begin{array}{l}\text { Impermeabilização da face superior da laje de cobertura e das faces laterais das grandes vigas } \\
\text { estruturais e invertidas de concreto da cobertura }\end{array}$ \\
\hline Procedimentos & $\begin{array}{l}\text { 1. Limpeza e preparação do substrato; } \\
\text { 2. Aplicação de fita tipo"crepe" sobre eventuais fissuras; } \\
\text { 3. Aplicação de revestimento tipo poliuréia; }\end{array}$ \\
\hline Intervenção & Reabilitação da face inferior da laje de concreto da cobertura (teto) \\
\hline Procedimentos & $\begin{array}{l}\text { 1. Perfurações e drenagem da água acumulada; } \\
\text { 2. Procedimento de reparação, seguindo os passos mostrados anteriormente } \\
\text { 3. Procedimento de proteção superficial; } \\
\text { 4. Lixamento da superfície; } \\
\text { 5. Limpeza geral do substrato; } \\
\text { 6. Estucamento da superfície (calafetamento); } \\
\text { 7. Aplicação de hidrofugante na superfície. }\end{array}$ \\
\hline Intervenção & Reabilitação da empena perimetral e dos pilares de concreto armado da fachada \\
\hline Procedimentos & $\begin{array}{l}\text { 1. Limpeza da superfície de concreto aparente; } \\
\text { 2. Remoção especial das manchas; } \\
\text { 3. Procedimento de reparação, seguindo os passos mostrados anteriormente }\end{array}$ \\
\hline
\end{tabular}
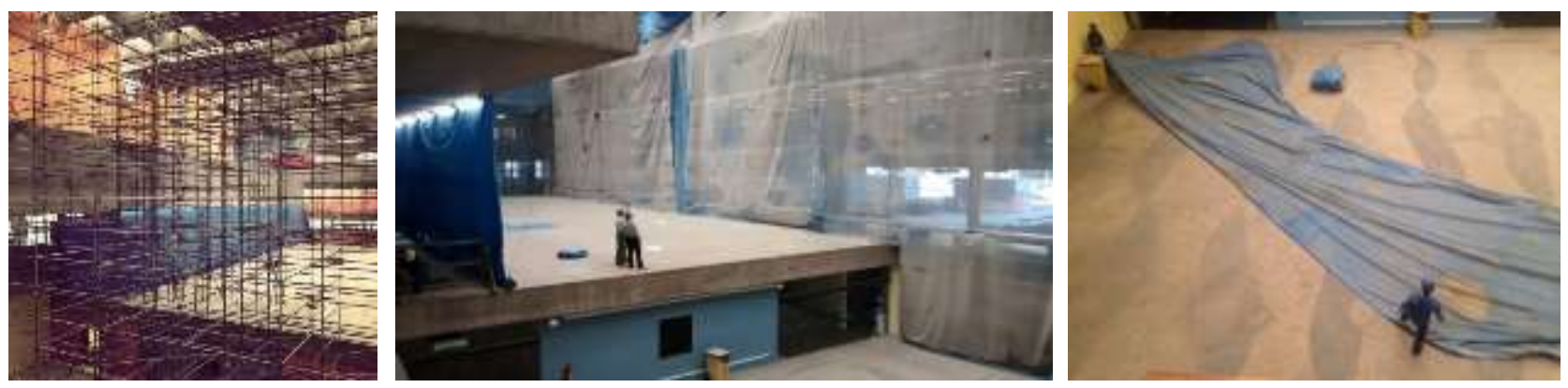

Figura 11 - Intervenções corretivas realizadas entre 2012 e 2015. Fotos: Divulgação (em www.facebook.com/fauusp)

\section{Conclusões}

Mesmo aparentando melhorias nas condições do edifício, as correções paliativas ao longo do tempo não se mostraram adequadas. A conservação da estrutura de concreto do edifício da FAUUSP depende de constante manutenção, de forma estruturada e programada. Mesmo assim, nota-se que algumas das intervenções realizadas ao longo do tempo foram fundamentais para garantir os parâmetros de segurança e estabilidade da estrutura, principalmente nos elementos considerados como prioritários e essenciais para o alcance da vida útil desejada. É preciso, no entanto, considerar a importância da reabilitação completa da edificação, conforme ocorrido na última intervenção, para que a preservação do patrimônio seja garantida.

Ao analisar a estrutura do edifício Vilanova Artigas, podemos explorar a importância dele não só como registro histórico da Arquitetura Moderna Brasileira, mas também sua contribuição para o protagonismo da estrutura na arquitetura brutalista. As análises e inspeções realizadas em importantes obras como esta contribuem para a memória do patrimônio moderno brasileiro, além de sugerir diretrizes para sua preservação. 


\section{Referências Bibliográficas}

ABNT NBR- 6118 (2014). Projeto de estruturas de concreto - Procedimento. Associação Brasileira de Normas Técnicas.

ABNT NBR-6120 (2000). Cargas para o cálculo de estruturas de edificações. Associação Brasileira de Normas Técnicas.

ANTUNES, J. S.; BRITEZ, C. A.; HELENE, P. (2010). "Edifício Vilanova Artigas". Projeto e especificação técnica dos serviços de reabilitação da estrutura de concreto armado do Edifício Vilanova Artigas da Faculdade de Arquitetura e Urbanismo da Universidade de São Paulo, Cobertura, teto e fachada. Relatório Técnico PhD 136 / 2010. PhD Engenharia Ltda. São Paulo, 2010.

GIANNECCHINI, A. C. (2009). Técnica e estética no concreto armado. Um estudo sobre os edifícios do MASP e da FAUUSP. Dissertação de Mestrado. 305 p. Faculdade de Arquitetura e Urbanismo de São Paulo. São Paulo, 2009.

PASQUA, J. F. S. (2017). O Papel da Estrutura na Definição da Arquitetura - Estudo de Caso do Prédio da FAU/USP. Monografia apresentada como requisito parcial para obtenção do título de Especialista. Curso de pós-graduação lato sensu em Reabilitação Ambiental Sustentável Arquitetônica e Urbanística. Programa de Pesquisa e Pós-graduação. Faculdade de Arquitetura e Urbanismo. Universidade de Brasília. Orientador: Prof. Dr. Márcio Augusto Roma Buzar. Brasília, 2017.

REBELLO, Y. C. P., (2000). A Concepção Estrutural e a Arquitetura. Zigurate, São Paulo, 2000. 